Original Research Article

\title{
Adverse drug reactions monitoring of newer oral hypoglycemic drugs in a tertiary care hospital of North India: a prospective study
}

\author{
Shephali Singh $^{1}$, Nilam Nigam ${ }^{1 *}$, Shalini Gupta ${ }^{1}$, Shravan Kumar ${ }^{2}$
}

\begin{abstract}
${ }^{1}$ Department of Pharmacology, ${ }^{2}$ Department of Medicine, Rama Medical College Hospital and Research Centre, Kanpur, Uttar Pradesh, India
\end{abstract}

Received: 28 July 2017 Accepted: 23 August 2017

\section{*Correspondence to: Dr. Nilam Nigam, Email: nigamrama36@ gmail.com}

Copyright: (C) the author(s), publisher and licensee Medip Academy. This is an openaccess article distributed under the terms of the Creative Commons Attribution NonCommercial License, which permits unrestricted noncommercial use, distribution, and reproduction in any medium, provided the original work is properly cited.

\begin{abstract}
Background: Diabetes Mellitus (DM) is a metabolic disorder characterized by hyperglycemia. In majority of patients oral hypoglycemic drugs remain the primary agents in management of DM. Currently there are variety of new drugs are approved in management of DM of which safety is established in clinical trials but there surveillance is needed for reporting newer adverse effects which are not documented yet.

Methods: 112 patients were screened with the help of a predefined inclusion and exclusion criteria for the study and followed up for three months. The drugs which are relatively new and have been in the market for around 5-7 years were taken as new drug. These include specifically the following drugs: DPP-IV Inhibitors, PPAR $\alpha / \gamma$ agonist, SGLT-2 inhibitors. They were screened and investigated suitably for any ADRs. The severity of the adverse drug reactions was graded according to the Hartwig's Severity Assessment Scale and Naranjo Scale was used for causality assessment between the drug and suspected reaction.

Results: Maximum ADRs reported belonged to gastro intestinal system (53\%). DPP-IV inhibitors showed maximum number of ADRs i.e. 70.6\%. Majority of ADRs reported were mild i.e. 52.9\%. Overall 15.2\% patients reported ADRs. Majority of ADRs reported (70.6\%) belonged to category 'possible'.

Conclusions: All three class of newer oral hypoglycemics seems reasonably safe to be used in general practice. As the number of patients were small, we need larger study to substantiate the findings.
\end{abstract}

Keywords: DPP-IV Inhibitors, PPAR $\alpha / \gamma$ agonist, SGLT-2 inhibitors

\section{INTRODUCTION}

Diabetes Mellitus (DM) is a chronic metabolic disorder characterized by hyperglycemia and associated with a high risk of numerous complications. It is estimated that 366 million people had DM in 2011; by 2030 this would have risen to 552 million. ${ }^{1}$ Classically having two varieties that is and Type $1 \mathrm{DM}$ also called insulin dependent diabetes mellitus (IDDM) Type 2 DM also called non-insulin dependent diabetes mellitus (NIDDM). Type 1 DM results from autoimmune destruction of pancreatic $\beta$-cells, leading to deficiency of insulin secretion. Type 2 DM results from interaction between genetic, environmental and behavioral risk factors while Monogenic forms like Maturity-onset diabetes of the young (MODY), constitutes up to $5 \%$ of cases. ${ }^{2,3}$ Type 2 diabetes is the predominant form of diabetes and accounts for at least $90 \%$ of all cases of diabetes mellitus. ${ }^{4}$ Gestational diabetes mellitus is getting common and obesity and is increasing in frequency throughout the world. As the prevalence of type 2 diabetes increases within a population so will the prevalence of GDM. ${ }^{5}$

Modern principles of management of diabetes focus on disease prevention, screening high risk individuals and aggressive treatment of individuals in the pre-diabetic state along with Medical Nutrition Therapy. The current 
pharmacotherapy of diabetes mellitus includes treatment with drugs such as insulin and oral hypoglycemic agents. Variety of oral antidiabetic agents are now available for the treatment of persons with type 2 diabetes: insulin secretagogues, biguanides, thiazolidinediones, $\alpha$ glucosidase inhibitors, incretin-based therapies, an amylin analog, and a bile acid binding sequestrant. The sulfonylureas and biguanides are the traditional treatment choice for type 2 diabetes. Insulin secretagogues increase insulin secretion from beta cells. Biguanides decrease hepatic glucose production. The thiazolidinediones reduce insulin resistance. The amylin analog also decreases postmeal glucose levels and reduces appetite. Alphaglucosidase inhibitors slow the digestion and absorption of starch and disaccharides. Newer drugs approved are SGLT-2 inhibitors e.g. Dapaglifozin, PPAR- $\alpha / \gamma$ agonist e.g. Saroglitazar and DPP4 inhibitors e.g. Sitagliptin etc. As the study targets newer agents only, we will mainly focus on them.

\section{Dipeptidyl-Peptidase IV inhibitors (DPP IV inhibitors)}

Sitagliptin and alogliptin are competitive inhibitors of DPP-4, whereas vildagliptin and saxagliptin bind the enzyme covalently. This causes a greater than 2-fold elevation of plasma concentrations of active incretins and is associated with increased insulin secretion, reduced glucagon levels, and improvements in both fasting and postprandial hyperglycemia. The DPP-4 inhibitors are well tolerated, carry a low risk of producing hypoglycemia and are weight neutral. However, they are relatively expensive. ${ }^{6}$ The long-term durability of effect on glycemic control and beta-cell morphology and function remain to be established. ${ }^{7}$

\section{Sodium Glucose co-transporters (SGLT-2) inhibitors}

Glucose is reabsorbed in the proximal convoluted tubule (PCT). This is achieved by facilitated glucose transporters (GLUTs), and active co-transporters, namely, sodiumglucose co-transporters (SGLTs). There are six identified SGLTs, of which two (SGLT1 and SGLT2) are considered most important. ${ }^{8}$ Sodium-glucose co-transporter-2 inhibitors act by inhibiting SGLT2 in the PCT, and decrease reabsorption of glucose and facilitate its excretion in urine. As glucose is excreted, its plasma levels fall leading to an improvement in all glycemic parameters. ${ }^{9,10}$ There is minimal potential for hypoglycemia, and no risk of overstimulation or fatigue of the beta cells. ${ }^{11}$ Sodium-glucose co-transporter-2 inhibitors use leads to weight reduction, about 1 to $5 \mathrm{~kg}$ which is more pronounced in patients with long-standing diabetes and higher baseline weight. ${ }^{12}$

\section{Peroxisome Proliferator Activated Receptor (PPAR)- $\alpha / \gamma$ agonist}

Saroglitazar is the novel molecule approved in India for the management of Diabetic dyslipidemia (DD). It is the first dual peroxisome proliferator activated receptor
(PPAR)-a $/ \gamma$ agonist to have successfully completed its clinical research and to be approved for clinical use anywhere in the world. There has been a $46.7 \%$ decrease in trigltcerides, $32.5 \%$ decrease in non-HDL-C, $0.3 \%$ absolute reduction in glycosylated hemoglobin (HbA1c). ${ }^{13,14}$ With increasing cases of lifestyle disorders along with diabetic dyslipidemia, saroglitazar is bound to help several patients suffering from it. Simultaneous agonistic activity on PPAR- $\alpha$ and PPAR- $\gamma$ is a novel treatment option for diabetic dyslipidemia and other such discoveries in this area shall benefit many.

ADRs can occur in all settings where healthcare is provided. Current conceptual thinking on the safety of patients places the prime responsibility for ADRs on deficiencies in system design, organization and operation - rather than on individual practitioners or products. Once marketed, a drug loses the scientific environment of clinical trials and is legally set free for consumption by the public. ${ }^{15}$ At this point, most drugs will only have been tested for short-term safety on a limited number of previously defined and selected individuals. ADR is defined as a response to a drug which is noxious and unintended, and which occurs at doses normally used in man for the prophylaxis, diagnosis, or therapy of disease, or for the modification of physiological function. ${ }^{16}$ ADRs are one of the leading causes of morbidity and mortality in healthcare. ADRs are a significant public health problem in the world. Not only do ADRs cause death and injury but they also affect the length of stay in hospitals which in turn leads to increased healthcare costs and decreased patient productivity. The rate of ADRs has approached 27 per 100 patients. ${ }^{17}$ ADR reporting has yet to be developed adequately. The need for increased awareness of the importance of ADR reporting is vital. Adverse drug reactions are ranked as one of the top 10 causes of morbidity and mortality in the developed world. ${ }^{18}$ However, the burden of the problem may actually be underestimated, as in many instances, ADRs are not suspected, thereby leading to under-reporting. ${ }^{19}$

Pharmacovigilance $(\mathrm{Pv})$ is an important tool for the safety and ensuring that the patients are safe in every aspect of the drugs being taken in any form. India as a growing part in pharmacovigilance and their activities is still in its nascent stage, there is a lot to be done in the field of Pharmacovigilance, in ensuring that the safe implementation of the activities. There is still a major part that goes underreporting in India. Moreover, rates of hospitalization of patients are increasing owing to adverse effects of drugs, and it becomes a challenge to find out the exact drugs causing the ADR's when a patient in treated with multiple drugs simultaneously.

Pharmacovigilance has been described as "the science and activities relating to the detection, assessment, understanding and prevention of the adverse effects of drugs or any other possible drug-related problems. It is a fundamental component of effective drug regulation systems, public health programmes and clinical 
practice". ${ }^{20}$ Pharmacovigilance supports safe and appropriate use of drugs by a) promoting the detection of previously unknown ADRs and interactions and increases in frequency of known ADRs, b) identifying risk factors for the development of ADRs and c) estimating quantitative aspects of benefit/risk analysis and disseminating information to improve drug prescribing and regulation. ${ }^{21}$ The establishment of a pharmacovigilance system is essential to support public health policy.

\section{METHODS}

The study was conducted by the Department of Pharmacology, in association with department of Medicine in Rama Medical College and Research Centre Kanpur, U.P. The study was conducted for duration of 12 months and patients were followed for three months. The study was conducted in accordance with the principles of Good Clinical Practice (GCP). The patients diagnosed with Type 2 diabetes attending Medicine outpatient clinic of Rama Medical College and Research Centre and on treatment with at least one newer oral anti-diabetic drug were screened for possible inclusion in the study. They were screened with the help of a predefined inclusion and exclusion criteria for the study. The drugs which are relatively new and have been in the market for around 5-7 years were taken as new drug. These include specifically the following drugs: DPP-IV inhibitors: gliptinssitagliptin, saxagliptin, and their combinations with metformin, PPAR $\alpha / \gamma$ agonist: saroglitazar. SGLT-2 inhibitors: dapagliflozin were introduced in the market later on and hence included subsequently during the course of the study. All patients were asked to follow up at monthly interval and whenever they develop any side effect. They were screened clinically and investigated suitably for any ADRs. All ADRs reported were submitted to ADR monitoring centre under Pharmacovigilance Programme of India (PvPI).

\section{Inclusion criteria}

- $\quad$ Patients of $>18$ yrs age of either sex diagnosed to have Type 2 diabetes.

- $\quad$ Patients with T2DM currently were taking at least one newer oral anti-diabetic drug.

\section{Exclusion criteria}

- Diabetic patients not taking the newer oral antidiabetic drugs.

- Newly diagnosed naïve diabetic patients.

- Patients with chronic co-morbidities.

- Patients not willing to give consent.

\section{Adverse event (AE) monitoring}

Adverse event monitoring was carried out by Spontaneous reporting. The patient's data including the demographic, clinical and biochemical details was entered into patient's case record form (CRF). The Central Drugs Standard Control Organisation (CDSCO) proforma was used and filled as and when AE was reported.

\section{ADR severity}

The severity of the adverse drug reactions was graded according to the Hartwig's Severity Assessment Scale which is as under.

\section{Hartwig's severity assessment scale ${ }^{22}$}

- $\quad$ Level 1 An ADR occurred but required no change in treatment with the suspected drug.

- Level 2 The ADR required that treatment with the suspected drug be held, discontinued, or otherwise changed. No antidote or other treatment requirement was required. No increase in length of stay (LOS)

- Level 3 The ADR required that treatment with the suspected drug be held, discontinued, or otherwise changed. AND/OR

- An Antidote or other treatment was required. No increase in length of stay (LOS)

- Level 4 Any level 3 ADR which increases length of stay by at least 1-day OR

- The ADR was the reason for the admission

- Level 5 Any level 4 ADR which requires intensive medical care

- $\quad$ Level 6 The adverse reaction caused permanent harm to the patient

- Level 7 The adverse reaction either directly or indirectly led to the death of the patient.

Mild $=$ level 1 and 2, moderate $=$ level 3 and 4, severe $=$ 5, 6 and 7

\section{Causality assessment of ADRs}

In the present study, Naranjo Scale will be used to analyse the causality assessment between the drug and suspected reaction.

\section{Naranjo scale}

According to Naranjo Criteria, the ADRs are analysed on the basis of a questionnaire comprising 10 questions in which each question is given a score of $+2,+1,0$ or -1 depending on the analysis. When totalled if the score is $>9$ - labelled as definite ADR, if 5-8 - probable ADR, if 1-4 possible ADR, if 0 - doubtful ADR. ${ }^{23}$ The classification of all the ADRs into different system organ class (SOC) involved was done according to the WHO-ART classification. The ADRs were categorized into gastrointestinal system disorders, musculoskeletal disorders, metabolic disorders, CNS disorders, genito-urinary disorders and few ADRs were categorized as "others" which could not be classified under any SOC. 


\section{RESULTS}

This observational study was conducted between November 2015 and November 2016. A total of 152 cases were recruited and eventually 112 remain in follow up. All Patients were also taking conventional oral hypoglycemic agents and no patient was prescribed insulin.

Table 1: Demographic profile of the patients on newer Oral Hypoglycemic Agents (OHAs).

\begin{tabular}{|c|c|c|c|}
\hline Parameter & Group & $\begin{array}{l}\text { No. of } \\
\text { patients }\end{array}$ & $\begin{array}{l}\% \text { of } \\
\text { patients }\end{array}$ \\
\hline \multirow{6}{*}{$\begin{array}{l}\text { Age years } \\
(\mathrm{MEAN} \pm \mathrm{SD}) \\
\text { Mean } \\
41.5 \pm 12.1\end{array}$} & 21-30 years & 28 & 25 \\
\hline & $31-40$ years & 21 & 18.8 \\
\hline & 41-50 years & 43 & 38.4 \\
\hline & 51-60 years & 13 & 11.6 \\
\hline & $61-70$ years & 06 & 5.3 \\
\hline & $>70$ years & 01 & 0.9 \\
\hline \multirow{2}{*}{ Gender } & Male & 60 & 53.5 \\
\hline & Female & 52 & 46.5 \\
\hline \multirow{4}{*}{ Drug Abuse } & Smoking & 21 & 27.7 \\
\hline & Tobacco & 29 & 38.2 \\
\hline & Alcoholism & 26 & 34.2 \\
\hline & Others & 00 & 00 \\
\hline \multirow{2}{*}{$\begin{array}{l}\text { Family history } \\
\text { of T2DM }\end{array}$} & Yes & 45 & 40.1 \\
\hline & No & 67 & 59.9 \\
\hline \multicolumn{4}{|c|}{$\begin{array}{l}\text { Weight }(\mathrm{Kg})(\mathrm{MEAN} \pm \mathrm{SD}) \\
63.1 \pm 10.3\end{array}$} \\
\hline \multicolumn{4}{|c|}{$\begin{array}{l}\text { Height }(\mathrm{cm})(\text { MEAN } \pm \text { SD }) \\
161 \mathrm{~cm} \pm 9.4\end{array}$} \\
\hline
\end{tabular}

Table 2: Clinical and drug profile of the patients on newer Oral Hypoglycemic Agents (OHAs).

\begin{tabular}{|c|c|c|c|}
\hline Parameter & Group & $\begin{array}{l}\text { No. of } \\
\text { patients }\end{array}$ & $\begin{array}{l}\% \text { of } \\
\text { patients }\end{array}$ \\
\hline \multirow{5}{*}{$\begin{array}{l}\text { Duration of } \\
\text { T2DM }\end{array}$} & $<5$ years & 32 & 28.6 \\
\hline & 5-10 years & 46 & 41.1 \\
\hline & $11-15$ years & 20 & 17.9 \\
\hline & $16-20$ years & 12 & 10.8 \\
\hline & $>20$ years & 02 & 1.6 \\
\hline \multirow{4}{*}{ Drug category } & Sitagliptin & 51 & 45.5 \\
\hline & Saxagliptin & 29 & 25.9 \\
\hline & Saroglitazar & 10 & 9 \\
\hline & Dapaglifozin & 22 & 19.6 \\
\hline \multirow{3}{*}{$\begin{array}{l}\text { No. of newer } \\
\text { OHAs taken }\end{array}$} & 1 & 95 & 84.8 \\
\hline & 2 & 17 & 15.2 \\
\hline & 3 & 00 & 00 \\
\hline \multirow{2}{*}{$\begin{array}{l}\text { Concomitant } \\
\text { other anti- } \\
\text { diabetic drugs }\end{array}$} & Older OHAs & 112 & \\
\hline & Insulin & 00 & \\
\hline \multirow{3}{*}{$\begin{array}{l}\text { Fasting plasma } \\
\text { glucose } \\
(\mathrm{mg} / \mathrm{dl})\end{array}$} & $126-150$ & 32 & 28.6 \\
\hline & $151-180$ & 56 & 50 \\
\hline & $>180$ & 24 & 21.4 \\
\hline \multirow{3}{*}{$\begin{array}{l}\text { 2-h Plasma } \\
\text { Glucose } \\
(\mathrm{mg} / \mathrm{dl})\end{array}$} & $201-225$ & 37 & 33 \\
\hline & $226-250$ & 56 & 50 \\
\hline & $>250$ & 21 & 17 \\
\hline \multirow{3}{*}{$\mathrm{HbA} 1 \mathrm{C} \%$} & $6.5-7$ & 30 & 26.8 \\
\hline & $7-8$ & 59 & 52.7 \\
\hline & $>8$ & 23 & 20.5 \\
\hline
\end{tabular}

Table 3: ADRs with different classes of newer oral anti-diabetic drugs as per the involvement of different system organ class (SOC).

\begin{tabular}{|c|c|c|c|c|c|}
\hline System organ class & $\begin{array}{l}\text { Adverse drug } \\
\text { reaction }\end{array}$ & $\begin{array}{l}\text { DPP-IV inhibitors } \\
\text { (80) }\end{array}$ & $\begin{array}{l}\text { SGLT-2 inhibitors } \\
\text { (22) }\end{array}$ & $\begin{array}{l}\text { PPAR- } \gamma \text { agonist } \\
\text { (10) }\end{array}$ & Total \\
\hline \multirow{6}{*}{$\begin{array}{l}\text { Gastro-intestinal } \\
\text { tract disorders }\end{array}$} & Diarrhoea & 04 & 01 & - & \multirow{2}{*}{09} \\
\hline & Constipation & - & - & - & \\
\hline & Dyspepsia & - & - & - & \\
\hline & Abdominal Pain & 01 & - & - & \\
\hline & Gastritis & - & - & 01 & \\
\hline & Nausea / Vomiting & 02 & - & - & \\
\hline Metabolic disorders & Hypoglycemia & 01 & - & - & 01 \\
\hline \multirow{3}{*}{$\begin{array}{l}\text { Musculoskeletal } \\
\text { disorders }\end{array}$} & Joint pain & 02 & - & \multirow{3}{*}{ - } & \multirow{3}{*}{04} \\
\hline & Myalgia & - & - & & \\
\hline & Fatigue & 01 & 01 & & \\
\hline \multirow{2}{*}{ CNS disorders } & Headache & 01 & - & - & \multirow{2}{*}{01} \\
\hline & Dizziness & - & - & - & \\
\hline \multirow{3}{*}{$\begin{array}{l}\text { Genito-urinary tract } \\
\text { disorders }\end{array}$} & Burning micturition & - & 02 & - & \multirow{3}{*}{02} \\
\hline & $\begin{array}{l}\text { Increased frequency } \\
\text { of urination }\end{array}$ & - & - & - & \\
\hline & Pus cells in urine & - & - & - & \\
\hline Total & & 12 & 04 & 01 & 17 \\
\hline
\end{tabular}


Table 1 shows the demographic profile of patients. The mean age of patients was 41.5 years with $53.5 \%$ patients were male. Maximum number of patients (38.4\%) belonged to age group of 41-50 years. The mean weight of the patients was $63.1 \mathrm{~kg}$ with average height $161 \mathrm{~cm}$. $40.1 \%$ patients were having family history of T2DM rest were diagnosed for the first time in their family. Substance abuse was common and commonest being tobacco chewing $38.2 \%$.

Table 2 represents clinical and drug profile of the patients. Majority of patients $(41.1 \%)$ were having duration of illness between 5-10 years. Among newer oral hypoglycemic agents DPP-IV inhibitors were most frequently prescribed $(71.4 \%) .15 .2 \%$ were taking two newer oral hypoglycemic agents. $50 \%$ of patients having fasting plasma glucose between $151-180 \mathrm{mg} / \mathrm{dl}$. $50 \%$ of patients were having 2-h plasma glucose between 226-250 $\mathrm{mg} / \mathrm{dl}$. HbA1C also followed similar trend as $52.7 \%$ of patients were having $\mathrm{HbA} 1 \mathrm{C}$ between $7-8 \%$.

Table 3 represents, ADRs with different classes of newer oral anti-diabetic drugs as per the involvement of different system organ class (SOC). Maximum ADRs reported belonged to gastro intestinal system that is 53\%. DPP-IV inhibitors showed maximum number of ADRs i.e. 70.6\%. Diarrhoea was found to be the most common encountered adverse drug reaction.

Table 4: Severity assessment of ADRs with different classes of newer oral anti-diabetic drugs. (Hartwig's Severity Assessment Scale).

\begin{tabular}{|llll|}
\hline & $\begin{array}{l}\text { DPP-IV } \\
\text { inhibitors } \\
(\mathbf{8 0})\end{array}$ & $\begin{array}{l}\text { SGLT-2 } \\
\text { inhibitors } \\
(\mathbf{2 2})\end{array}$ & $\begin{array}{l}\text { PPAR- } \boldsymbol{l} \\
\text { agonist } \\
(\mathbf{1 0})\end{array}$ \\
\hline Mild & 07 & 02 & 0 \\
\hline Moderate & 05 & 02 & 01 \\
\hline Severe & 0 & 0 & 0 \\
\hline Total & 12 & 04 & 01 \\
\hline
\end{tabular}

Table: 5 Causality assessment of ADRs with different classes of newer oral anti-diabetic drugs according to Naranjo scale.

\begin{tabular}{|lllll|}
\hline $\begin{array}{l}\text { Newer } \\
\text { OHAs }\end{array}$ & Certain & Probable & Possible & Unlikely \\
\hline $\begin{array}{l}\text { DPP-IV } \\
\text { inhibitors }\end{array}$ & 0 & 02 & 10 & 0 \\
$(12)$ & 02 & 02 & 0 \\
\hline $\begin{array}{l}\text { SGLT-2 } \\
\text { inhibitors } \\
(04)\end{array}$ & 0 & 01 & 0 & 0 \\
\hline $\begin{array}{l}\text { PPAR- } \gamma \\
\text { agonist } \\
(01)\end{array}$ & 0 & 01 & & \\
\hline
\end{tabular}

Table 4 shows severity assessment of ADRs with different classes of newer oral anti-diabetic drugs. Majority of
ADRs reported were mild i.e. 52.9\% and no severe ADR was reported.

Table 5 represents causality assessment of ADRs with different classes of newer oral anti-diabetic drugs according to Naranjo scale. Majority (70.6\%) ADRs were having possible correlation with the drug. No certain causal relation was established.

\section{DISCUSSION}

Current study was planned to actively generate data on the safety profile of currently prescribed newer oral antidiabetic drugs among type 2 diabetic patients by spontaneous ADR monitoring. In the current study, out of 80 patients on DPP-IV inhibitors, ADRs were reported in $15 \%$. Kajiwara et al, evaluated safety profile of DPP-IV inhibitors in 1550 patients and reported an incidence of $5.9 \%$ ADRs. $^{24}$ As regards with 10 patients on PPAR- $\alpha / \gamma$ agonist: saroglitazar, ADRs were reported in $10 \%$. The incidence of ADRs with saroglitazar in the present study was in accordance with a similar study by Chatterjee et al which demonstrated $11.8 \%$ of ADRs with saroglitazar. ${ }^{25}$

\section{DPP-IV inhibitors}

Out of 12 ADRs reported due to DPP-IV inhibitors, it was seen that gastro-intestinal (GI) system disorders constituted the maximum number $(58.3 \%)$ followed by musculoskeletal (25\%). A study by Kajiwara et al, also showed that the maximum number of ADRs with DPP-IV inhibitors was on GI system which is on similar pattern with present study. $^{24}$ The incidence of diarrhoea constituted the maximum number of ADRs due to GI involvement by DPP-IV inhibitors. Most of the ADRs were usually mild and either subsided with time or on dose reduction. The results were consistent with that of the present study where the maximum incidence of GI related ADRs were seen with combination of sitagliptin.

With saxagliptin, out of 5 reported ADRs, 3 were attributed due to involvement of GI system: In a study by De Fronzo et al which assessed the safety of saxagliptin as add-on therapy in type 2 diabetic patients, it was seen that incidence of adverse events related to gastrointestinal disorders was similar in patients treated with saxagliptin (23.0\%) versus placebo plus metformin (24.0\%) and saxagliptin was not associated with an increased incidence of gastrointestinal disorders as compared to placebo. ${ }^{26}$ In the present study, 01 ADR of hypoglycemia was reported amongst 80 patients on DPP-IV inhibitors. These patients were on concomitant treatment with conventional OHAs. No episode of hypoglycemia exhibited marked severity. These findings are in accordance with those of the study conducted by Goossen and Graber who observed that hypoglycemic risk was similar to placebo when a DPP-IV inhibitor was used as monotherapy or as combination therapy with metformin. ${ }^{27}$ Overall, studies show a low risk of hypoglycaemia during treatment with DPP-IV 
inhibitors which does not mandate a discontinuation of treatment.

In current study, $25 \%$ of ADRs with DPP-IV inhibitors were due to involvement of musculoskeletal system. Both fatigue and joint pain were mild and subsided in due course of time and did not lead to treatment discontinuation. Tarapues et al, reported that musculoskeletal disorders are adverse reactions often associated with gliptins that despite not being serious, may impair the treatment adherence in patients with type 2 diabetes. ${ }^{28} 8.3 \%$ of ADRs with DPP-IV inhibitors were due to involvement of CNS. Goossen and Graeber have also reported that treatment with DPP-IV inhibitors was associated with a slightly elevated risk for nervous system disorders, mainly dizziness and headache in comparison to placebo and showed that the risk was not increased compared to other antidiabetic drugs. ${ }^{27}$ As a whole, DPP-IV inhibitors appear to have a good safety profile for patients with type 2 diabetes. However, close pharmacovigilance is necessary to further confirm the association of drugs and ADRs.

\section{PPAR a/y agonist}

In the present study, out of 10 patients on saroglitazar, adverse drug reactions were noted in 01 patient $(10 \%)$. There was one ADR of gastritis. PRESS V (Prospective Randomized Efficacy and Safety of Saroglitazar V) also showed incidences of similar ADRs. It was the first prospective confirmatory clinical study of saroglitazar in diabetic dyslipidemia. ${ }^{29}$ In another multicenter study to evaluate the efficacy and safety of different doses of saroglitazar versus placebo (PRESS VI), gastritis was reported to be most common adverse effect. ${ }^{30}$ These studies did not provide any possible explanation of association of gastritis or fatigue with saroglitazar use but reported that the ADRs due to saroglitazar were mild to moderate in intensity. Our findings are similar to these studies. Saroglitazar seems to be safe and well tolerated in management of diabetic dyslipidaemia but the fact must not be generalized as the number of patients were very less to have a valid conclusion.

\section{SGLT-2 inhibitors}

Amongst 22 patients on SGLT-2 inhibitors: adverse drug reaction monitoring documented 04 ADRs (23.5\%). Genito-urinary system disorders $(50 \%)$, was major contributor in ADRs. A 2013 meta-analysis furthers confirms this which state that when compared to other antidiabetes agents, urinary tract infections were more common with SGLT2 inhibitors as were genital tract infections. $^{31}$ These occurrences are usually mild to moderate and responsive to treatment and they rarely result in discontinuation of therapy. It appears logical that glucosuria, deliberately induced by SGLT2 inhibition, favours urinary tract infections, as glucose serves as nutrient for bacteria. Taken together, these results suggest that SGLT-2 inhibitors represent a valuable therapeutic option for the management of patients with type 2 diabetes.
Overall, the newer oral anti-diabetic drugs appear to be a safe option for patients with type 2 diabetes.

\section{CONCLUSION}

Diabetes Mellitus is affecting India badly leading to increased morbidity with increasing treatment cost. With increasing medication chances of ADRs increase which also contribute to morbidity and loss of productivity. Good counselling about ADRs and early reporting to physician are key to avoid such predictable ADRs. Notifying ADRs to higher centres also contributes to safe use of drugs. The patients in the study were not much in number so to generalize statement to population will not be fair however it gives an idea about the prevalence of ADRs with newer oral hypoglycemic agents with their causal relationship with drug and severity. To achieve more valid conclusion large scale studies are required.

Funding: No funding sources

Conflict of interest: None declared

Ethical approval: The study was approved by the Institutional Ethics Committee

\section{REFERENCES}

1. Global burden of diabetes. International Diabetes federation. Diabetic atlas fifth edition 2011, Brussels. Available at: http://www.idf.org/diabetesatlas.

2. Chen L, Magliano DJ, Zimmet PZ. The worldwide epidemiology of type 2 diabetes mellitus: present and future perspectives. Nature reviews endocrinology.

3. Camastra S, Bonora E, Del Prato S, Rett K, Weck M, Ferrannini E. EGIR (European Group for the Study of Insulin Resistance). Effect of obesity and insulin resistance on resting and glucose-induced thermogenesis in man. Int J Obes Relat Metab Disord. 1999 Dec;23(12):1307-13.

4. González EL, Johansson S, Wallander MA, Rodríguez LA. Trends in the prevalence and incidence of diabetes in the UK: 1996-2005. J. Epidemiol. Community Health. 2009;63:332-6.

5. Hunt KJ, Schuller KL. The increasing prevalence of diabetes in pregnancy. Obstet Gynecol Clin North Am. 2007;34(2):173-99.

6. Pratley RE, Salsali A. Inhibition of DPP-4: A new therapeutic approach for the treatment of type 2 diabetes. Curr Med Res Opin, 2007 Apr;23(4):919-31.

7. Barnett A. DPP-4 inhibitors and their potential role in the management of type 2 diabetes. Int $\mathrm{J}$ Clin Pract. 2006 Nov;60(11):1454-70.

8. Abdul GM, DeFronzo R. Dapagliflozin for the treatment of type 2 diabetes. Expert Opin Pharmacother. 2013;14:1695-703.

9. Lee YJ, Lee YJ, Han HJ. Regulatory mechanisms of $\mathrm{Na}$ /glucose cotransporters in renal proximal tubule cells. Kidney Int Suppl. 2007;(106):S27-35.

10. Hummel CS, Lu C, Loo DD, Hirayama BA, Voss AA, Wright EM. Glucose transport by human renal 
NA?/D-glucose cotransporters SGLT1 and SGLT2. Am J Physiol Cell Physiol. 2011;300:C721.

11. Nauck MA. Update on developments with SGLT2 inhibitors in the management of type 2 diabetes. Drug Des Devel Ther. 2014;8:1335-80.

12. Scheen A. Pharmacokinetic and pharmacodynamic profile of empagliflozin, a sodium glucose cotransporter 2 inhibitor. Clin Pharmacokinet. 2014;53(3):213-25.

13. Jani RH, Pai V, Jha P, Jariwala G, Mukhopadhyay S, Bhansali A, et al. A multicenter, prospective, randomized, double-blind study to evaluate the safety and efficacy of Saroglitazar 2 and $4 \mathrm{mg}$ compared with placebo in type 2 diabetes mellitus patients having hypertriglyceridemia not controlled with atorvastatin therapy (PRESS VI). Diabetes technology \& therapeutics. 2014 Feb 1;16(2):63-71.

14. Jani RH, Pai V, Jha P, Jariwala G, Mukhopadhyay S, Bhansali A, et al. A multicenter, prospective, randomized, double-blind study to evaluate the safety and efficacy of saroglitazar 2 and $4 \mathrm{mg}$ Compared to pioglitazone $45 \mathrm{mg}$ in diabetic dyslipidemia (PRESS V). J Diabetes Sci Technol. 2014;8:132-41.

15. Russell A, Daneshtalab N, Lewanczuk RZ, Jamali F. Rheumatoid arthritis does not reduce the pharmacodynamic response to valsartan. J. Clin Pharmacol. 2004;44:245-52

16. Handbook of resolutions and decisions of the World Health Assembly and Executive Board, In: WHA16.36 Clinical and Pharmacological Evaluation of Drugs, vol. World Health Organization, Geneva; 1973:11948-1972.

17. Gandhi TK, Borus J, Burdick E, Poon EG, Seger AC, Weingart SN. Outpatient prescribing errors and the impact of computerized prescribing. J. Gen. Intern. Med. 2005;20(9):837-41.

18. Lazarou J, Pomeranz BH, Corey P. Incidence of adverse drug reactions in hospitalized patients: a metaanalysis of prospective studies. JAMA. 1998;279:1200-5.

19. Benkirane R, Pariente A, Achour S, Ouammi L, Azzouzi A, Soulaymani R. Prevalence and preventability of adverse drug events in a teaching hospital: a cross-sectional study. East Mediterr Health J. 2009;15:1145-55.

20. World Health Organization. Safety of medicines. A guide to detecting and reporting adverse drug reactions - why health professionals need to take action. Geneva: World Health Organization; 2002.

21. World Health Organization. Safety monitoring of medicinal products: guidelines for setting up and running a pharmacovigilance centre. Uppsala: Uppsala Monitoring Centre, World Health Organization; 2000.

22. Hartwig SC, Siegel J and Schneider PJ. Preventability and Severity Assessment in Reporting Adverse Drug reactions. American Journal of Hospital Pharmacy. 1992;49:2229-31.
23. Naranjo CA, Busto U, Sellers EM, Sandor P, Ruiz I, Roberts EA, et al. A method for estimating the probability of adverse drug reactions. Clinical Pharmacology \& Therapeutics. 1981 Aug 1;30(2):239-45.

24. Kajiwara A, Saruwatari J, Sakata M, Morita K, Kita A, Oniki K, et al. Risk factors for adverse symptoms during dipeptidyl peptidase-IV inhibitor therapy: a questionnaire-based study carried out by the Japan Pharmaceutical Association Drug Event Monitoring project in Kumamoto Prefecture. Drug Saf. 2013 Oct;36(10):981-7.

25. Chatterjee S, Majumder A, Subir R. Observational Study of Effects of Saroglitazar on Glycaemic and Lipid Parameters on Indian Patients with Type 2 Diabetes. Sci Rep. 2015;5:7706.

26. Defronzo RA, Hissa MN, Garber AJ, Gross JL, Duan RY, Ravichandran S. The efficacy and safety of saxagliptin when added to metformin therapy in patients with inadequately controlled type 2 diabetes with metformin alone. Diabetes care. 2009 Sept;32(9):1649-55.

27. Gooßen K, Gräber S. Longer term safety of dipeptidyl peptidase- 4 inhibitors in patients with type 2 diabetes mellitus: systematic review and meta-analysis. Diabetes Obes Metab. 2012 Dec;14(12):1061-72.

28. Tarapués M, Cereza G, Figueras A. Association of musculoskeletal complaints and gliptin use: review of spontaneous reports. Pharmacoepidemiol Drug Saf. 2013 Oct; 22(10):1115-8.

29. Pai V, Paneerselvam A, Mukhopadhyay S, Bhansali A, Kamath D, Shankar V, et al. A Multicenter, Prospective, Randomized Double-blind Study to Evaluate the Safet and Efficacy of Saroglitazar 2 and $4 \mathrm{mg}$ Compared to Pioglitazone $45 \mathrm{mg}$ in Diabetic Dyslipidemia (PRESS V). Journal of Diabetes Science and Technology. 2014;8(1):132-4.

30. Jani RH, Pai V, Jha P, Jariwala G, Mukhopadhyay S, Bhansali A, et al. A Multicenter, Prospective, Randomized, Double-Blind Study to Evaluate the Safety and Efficacy of Saroglitazar 2 and $4 \mathrm{mg}$ Compared with Placebo in Type 2 Diabetes Me llitus Patients Having Hypertriglyceridemia Not Controlled with Atorvastatin Therapy (PRESS VI). Diabetes Technology \& Therapeutics. 2014;16(2):63-71.

31. Vasilakou D, Karagiannis T, Athanasiadou E. Sodium-glucose cotransporter 2 inhibitors for type 2 diabetes: a systematic review and meta-analysis. Ann Intern Med. 2013;159(4):262-74.

Cite this article as: Singh S, Nigam N, Gupta S, Kumar S. Adverse drug reactions monitoring of newer oral hypoglycemic drugs in a tertiary care hospital of North India: a prospective study. Int $\mathbf{J}$ Basic Clin Pharmacol 2017;6:2434-40. 